\title{
BMJ Open Effects of prematurity on long-term renal health: a systematic review
}

\author{
Ananya Sangla (D) ,' Yogavijayan Kandasamy (D) ${ }^{2,3}$
}

To cite: Sangla A, Kandasamy Y. Effects of prematurity on long-term renal health: a systematic review. BMJ Open 2021;11:e047770. doi:10.1136/ bmjopen-2020-047770

- Prepublication history and additional supplemental material for this paper are available online. To view these files, please visit the journal online. (http://dx.doi.org/10.1136/ bmjopen-2020-047770).

Received 08 December 2020 Accepted 27 July 2021

Check for updates

(C) Author(s) (or their employer(s)) 2021. Re-use permitted under CC BY-NC. No commercial re-use. See rights and permissions. Published by BMJ.

${ }^{1}$ Monash University Faculty of Medicine, Nursing and Health Sciences, Clayton, Victoria, Australia

${ }^{2}$ Department of Neonatology, Townsville Hospital and Health Service, Townsville, Queensland, Australia

${ }^{3}$ The University of Newcastle, Callaghan, New South Wales, Australia

\section{Correspondence to} Dr Yogavijayan Kandasamy; Yogavijayan.Kandasamy@ newcastle.edu.au

\section{ABSTRACT}

Objective To investigate the literature and determine if prematurity has an impact on long-term adverse kidney outcomes.

Design Systematic review.

Data sources OVID Medline, PubMed, SCOPUS, CINAHL and EMBASE databases were searched for studies relating to the adverse outcomes of prematurity from 1990 to April 2021.

Eligibility criteria for selecting studies All articles published between January 1990 and April 2021 that investigated whether premature infants developed longterm adverse renal outcomes were included in this review. Articles must have been human studies and written in English. Case series with less than 20 participants and case studies were excluded.

Data extraction and synthesis One reviewer completed the database searches. Article selection was performed independently and in a non-blinded manner by both reviewers. Initial screening was by title and abstract. Full texts of remaining articles were reviewed. Articles for which inclusion was unclear were re-reviewed by both reviewers, and a unanimous decision was taken as to whether they should be included. The Newcastle-0ttawa Scale was used for quality assessment of the included articles.

Results The literature search yielded 31 human studies, which investigated the short-term and long-term kidney outcomes of prematurity. These studies were conducted in 17 different countries. The most common outcomes measured were blood pressure (BP) and glomerular filtration rate. Other common outcomes measured included kidney size and mass, proteinuria, albuminuria, chronic kidney disease (CKD) and physical parameters such as height, weight and body mass index.

Conclusion Prematurity is likely linked to increased risk of kidney dysfunction and high BP in childhood and into early adulthood. Premature birth conferred a twofold increased risk of CKD and extremely premature birth conferred a threefold increased risk of CKD. However, further larger multicentre studies are needed to draw definitive conclusions on the long-term kidney outcomes of prematurity.

\section{INTRODUCTION}

Prematurity is the leading cause of mortality in children under the age of $5 .{ }^{1}$ However, with advances in technology and modern medicine, both the incidence of prematurity and the number of ex-premature babies living into adulthood are increasing, especially in
Strengths and limitations of this study

- This systematic review yielded 31 relevant human studies from a wide search of five reputable databases.

- We used the Newcastle-0ttawa Scale to assess the quality of included studies.

- The long-term adverse outcomes of prematurity on kidney function can only be evaluated up to approximately 40 years of age, as research into the ageing population is still needed.

- As current research into the long-term kidney outcomes of prematurity is lacking, the available research is not sufficient to draw definitive conclusions as to the long-term kidney outcomes of premature children. Further larger multicentre studies are still needed.

population-dense countries. ${ }^{1}$ Approximately 15 million, or just over 1 in 10 babies, are born prematurely every year. ${ }^{2}$ The highest number of premature births are seen in India, China and Nigeria; while the highest rates of premature births are seen in Malawi, Comoros and Congo. ${ }^{3}$

Though premature birth is becoming more commonplace, it is not without its own challenges. The Barker hypothesis proposes that diseases of adulthood are due to factors pertaining to fetal life. ${ }^{4-6}$ This proposition is also commonly known as the Developmental Origins of Health and Disease (DOHaD) hypothesis. This conclusion was first drawn when Barker et al found that early death secondary to coronary artery disease was inversely related to weight at birth. ${ }^{7}$ Thus, the DOHaD paradigm was created. It proposed that developmental factors, including nutrition, stressors, and environmental exposures such as drugs and infections, could lead to functional changes in tissues which may predispose to disease in later life. ${ }^{8}$

The impact of prematurity on long-term kidney dysfunction or chronic kidney disease (CKD) is still not fully understood. Impaired nephrogenesis due to poor fetal growth, prematurity, antenatal and postnatal medication, and other factors most likely lead 
to reduced nephron endowment and CKD. ${ }^{9} 10$ Nephrogenesis is completed by 37 weeks of gestation, and the majority of nephrogenesis occurs in late gestation. ${ }^{11}$ Therefore, in premature neonates, nephrogenesis is terminated early conferring reduced nephron numbers. Nephrons do not regenerate. The number of functional nephrons over time decreases as part of normal ageing. ${ }^{5}$ As premature children are born with reduced nephron numbers, an increased risk of kidney dysfunction is postulated. Luyckx et al also proposed that as a compensatory measure for low nephron numbers, nephron surface area increases. This maladaptive response causes systemic hypertension and increased sodium retention, which in turn causes disrupted autoregulation. ${ }^{12}$ The resulting nephron sclerosis leads to increased functional nephron decline, creating a vicious cycle. ${ }^{12} 13$

As the ex-premature population is living longer and becoming part of the ageing population, understanding the effects of prematurity is imperative in anticipating the likely chronic health outcomes the premature population will face. This review is intended to investigate the literature to determine if a link is present between prematurity and adverse long-term kidney health. Identifying a link will be the first step in deciding how best to follow-up and manage ex-premature children and adults to prevent morbidity and premature mortality in the long term.

\section{METHODS}

This systematic review was completed in accordance with the Preferred Reporting Items for Systematic Reviews and Meta-Analyses guidelines. ${ }^{14}$ The systematic search was conducted using OVID Medline, PubMed, SCOPUS, CINAHL and EMBASE. The search criteria were developed and refined from January 2020 to April 2021. Relevant keywords were identified, and all relevant Medical Subject Headings (MeSH) and non-MeSH synonyms were included. Relevant keywords included prematurity, chronic kidney failure, CKD, kidney volume, proteinuria, albuminuria, hypertension, high blood pressure (BP), reduced glomerular filtration rate (GFR), decreased kidney function and long-term adverse outcomes. The final search was conducted on 1 April 2021. An example of the database search for OVID Medline can be seen in the online supplemental file 1 . Only articles published in English between January 1990 and April 2021 have been included. Animal studies were excluded. Finally, articles shortlisted for inclusion were screened for bias and re-evaluated for inclusion if there was significant bias.

Once the literature search was completed, article selection was performed independently and in a non-blinded manner by two reviewers. The articles were initially screened by title and then by the abstract. All remaining articles were reviewed and determined for inclusion based on examination of the full text. Articles that were unclear were re-reviewed by both reviewers, and a unanimous decision was taken as to whether they should be included.
Articles were included if they studied premature and/ or low birth weight infants to determine if they developed adverse kidney outcomes as a result of being premature. Studies that investigated low birth weight infants were only included if their low birth weight cohort was also premature. Outcomes that were evaluated included GFR, BP, tubular function, kidney length and volume, and urinary protein/albuminuria and electrolytes. Case series with less than 20 participants, and case studies would be excluded from this review as they would not provide the level of evidence or relevant information required. Included articles and their characteristics can be found in online supplemental table $1 .{ }^{15-45}$ Articles underwent quality assessment using the Newcastle-Ottawa Scale. ${ }^{46}$ This can be seen in table 1 .

\section{Patient and public involvement}

Patients were not involved in the development or design of this systematic review.

\section{RESULTS}

The collective search from the five databases revealed 1311 studies. A total of 1263 articles remained after duplicates were omitted. All 1263 articles were screened, and 1101 were excluded based on title and abstract. For the remaining 162 articles, full texts were assessed for eligibility. Sixty-four articles were excluded due to long-term adverse kidney outcomes not being investigated. Nine articles were excluded as prematurity or low birth weight were not investigated. Eight were excluded for being animal studies, and 50 were excluded for being case reports or case series with less than 20 participants. Thus, the literature search yielded 31 human studies which investigated the long-term kidney outcomes of prematurity. ${ }^{15-45}$ These studies were conducted in 17 different countries: Australia, Israel, Japan, Italy, Greece, Poland, France, Egypt, Sweden, Belgium, Mexico, the Netherlands, Scotland, Spain, the USA, Finland and Norway. ${ }^{15-45}$ A flow diagram demonstrating the selection process can be seen in figure 1 . The lead author surname, year of publication, sample size, birth weight, gestation, outcome measures, age at which outcome measured and conclusions of the selected studies can be seen in online supplemental table 1. A quality assessment of included studies was conducted using the Newcastle-Ottawa Scale and can be seen in table 1 .

Of the included studies, the smallest cohort size was 20, and the largest cohort size was $4193069 .^{1840}$ The youngest gestational age from the premature cohorts was 22 weeks, and the most mature gestational age for the premature cohorts was 36 weeks. ${ }^{374}$ The youngest age at which outcomes were measured was at birth, and the oldest age at which outcomes were measured was at 43 years. ${ }^{3740}$ The most common outcomes measured were BP and kidney function (GFR and proteinuria/ microalbuminuria). Other outcomes measured included kidney size and mass, urine analysis, CKD and physical 
Table 1 Quality assessment of included observation studies using the Newcastle-Ottawa Scale

\section{Cohort studies}

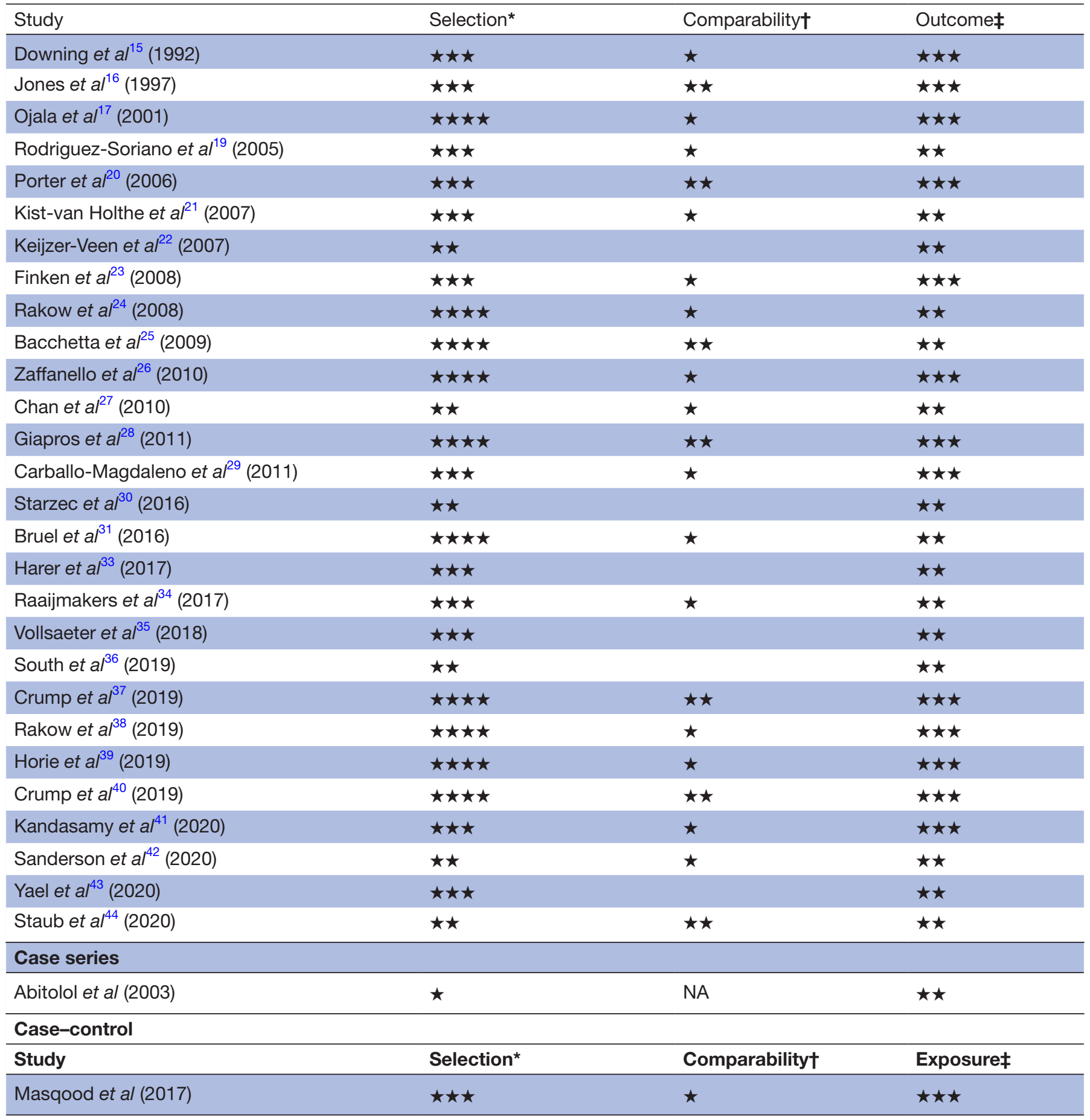

*Maximum four stars.

†Maximum two stars.

$\ddagger$ Maximum three stars.

parameters (height, weight and body mass index). Some studies also commented on insulin resistance and serum lipid profile.

\section{Glomerular filtration rate}

Twenty-seven out of the thirty-one studies investigated GFR as an outcome measure. ${ }^{16-3638394143-45}$ Ten of these twenty-seven studies compared premature children and term children. 19212224273536384144 Four found no significant difference in GFR while six did. Of the four studies that found no significant difference, Rakow et al measured their outcomes at 9 years, Kandasamy et al measured their outcomes at 0.5, 1 and 2 years, Staub et al measured GFR 

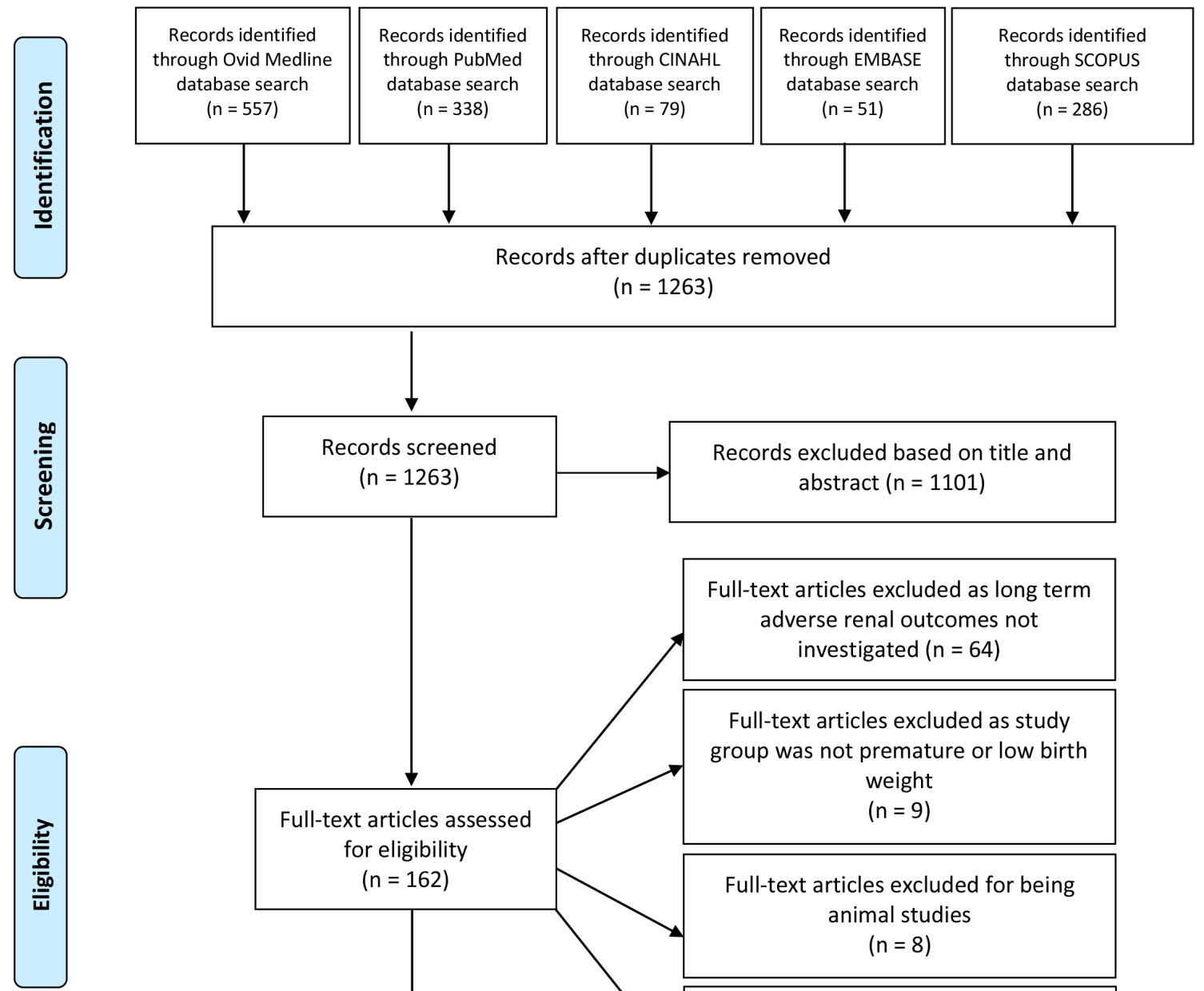

for eligibility

$(n=162)$

Full-text articles excluded for being animal studies

$(n=8)$

Full-text articles excluded as they were case reports or case series with less than 20 participants $(n=50)$

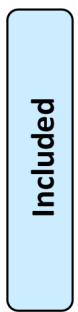

Studies included in qualitative synthesis $(n=31)$

Figure 1 Preferred Reporting Items for Systematic Reviews and Meta-Analyses flow diagram.

at 12 years and Chan et al measured outcomes at approximately 13.5 years. ${ }^{24} 274144$ Of the six studies that found a significantly decreased GFR in premature children, outcomes were measured at approximately 7.5 years, 8 years, 8.5 years, $11.5,14$ and 20 years, respectively, for Kist-Van Holthe et al, Rakow et al, Rodriguz-Soriano et al, Vollsaeter et al, South et al and Keijer Veen et al. ${ }^{19} 2122353638$ It should be noted that Keijer Veen $e t$ al found that GFR was significantly lower in the premature small for gestational age group compared with term controls at 20 years. ${ }^{22}$ This was not the case for the premature appropriate for gestational age group. ${ }^{22}$ When the small for gestational age group had their GFR adjusted for body surface area, there was no significant difference between groups. ${ }^{22}$

Twelve studies investigated GFR in study and control groups with differing characteristics including no term birth comparison. ${ }^{16-18} 2023252628$ 30-32 34 Seven of these studies found no statistically significant difference in GFR between study and control groups. ${ }^{17} 202628313234$ Ojala et al compared premature infants with and without indomethacin exposure in the neonatal period and measured outcomes at 2-4 years. ${ }^{17}$ Raaijmakers et al compared premature infants with and without ibuprofen exposure 
in the neonatal period and assessed outcomes at 11 years. ${ }^{34}$ Porter et al compared two groups of very low birth weight children with and without nephrocalcinosis at 5-7 years of age. ${ }^{20}$ Zaffanello compared very low birth weight and extremely low birth weight children at 5-6 years. ${ }^{26}$ Giapros compared premature infants with and without nephrocalcinosis for the first 2 years of life. ${ }^{28}$ Masqood $e t$ al compared three groups of extremely low birth weight children with no Acute Kidney Injury (AKI), stage 1 AKI and stage $2 \mathrm{AKI}$, and found no significant difference in the prevalence of diminished GFR values. ${ }^{32}$ Finally, Bruel et al found nil significant difference between premature children with and without neonatal AKI when assessed at 7 years of age. ${ }^{31}$ Bruel et al did, however, note that GFR was significantly lower in children with a birth weight less than $1000 \mathrm{~g}^{31}$

On the other hand, five of these studies did find significant differences in GFR between study and control groups. ${ }^{1618232530}$ Finken et alnoted significantly decreased GFR in premature infants who received betamethasone in the neonatal period when compared with premature infants who did not. ${ }^{23}$ This outcome was measured at 19 years of age. ${ }^{23}$ Abitbol et al found ex-premature children had normal GFRs when aged 5.7 years but children assessed at 9.9 years were found to have diminished GFR. ${ }^{18}$ Starzec et al concluded that GFR was significantly lower in the extremely low birth weight group compared with term controls when assessed at 11 years. ${ }^{30}$ Bacchetta $e t$ al found significantly decreased GFR in premature extrauterine growth retardation and intrauterine growth retardation when compared with premature normotrophic children at 7-8 years of age. ${ }^{25}$ Jones $e t$ al found that four out of their eleven premature babies with nephrocalcinosis had an abnormal GFR at 4-5 years of age. Jones et al did not, however, have a term control group to compare these results too. ${ }^{16}$

Only one study (Carballo-Magdaleno et al) found an increased GFR in premature infants when compared with term infants. Outcomes were measured at 2 years of age. ${ }^{29}$ Table 2 shows all the studies that investigated GFR and whether or not they found a significant difference between groups.

Four studies looked at the prevalence of low GFR in their premature cohorts. ${ }^{33} 394345$ Harer et al found that $26 \%$ of their 34 premature very low birth weight participants had an abnormally low eGFR using cystatin C at 5 years of age. ${ }^{33}$ Horie et al found that of their 168 premature children, $10.7 \%$ had persistently low GFR at $>2$ years of age. ${ }^{39}$ Yael et al found that $100 \%$ of their 103 study participants with a history of very low birth weight and premature birth had normal GFR values at 10-13 years of age. ${ }^{43}$ Askenazi et al found that of their 923 extremely premature study participants, $16 \%$ had a GFR $<90 \mathrm{~mL} /$ $\min / 1.73 \mathrm{~m}^{2}$ at $22-26$ months of age. ${ }^{45}$

\section{Chronic kidney disease}

Crump et al's study was the only study that exclusively investigated for CKD. ${ }^{37}$ From their large cohort size of 4
Table 2 A comparison of the studies that did and did not report a significant difference in GFR (listed in descending order of cohort size)

\begin{tabular}{|c|c|}
\hline $\begin{array}{l}\text { Studies that found a } \\
\text { significant difference in GFR } \\
\text { between groups }\end{array}$ & $\begin{array}{l}\text { Studies that did not find } \\
\text { a significant difference in } \\
\text { GFR between groups }\end{array}$ \\
\hline Askenazi et al ${ }^{45}$ (2021) & Masqood et al (2017) \\
\hline Finken et $a l^{23}(2008)$ & Staub et al ${ }^{44}(2020)$ \\
\hline Horie et $a l^{39}(2019)$ & Giapros et $a^{28}(2011)$ \\
\hline South et $a l^{36}(2019)$ & Rakow et al ${ }^{24}(2008)$ \\
\hline Vollsaeter et al ${ }^{35}$ (2018) & Yael et al ${ }^{43}(2020)$ \\
\hline Starzec et $\left.a\right|^{30}(2016)$ & Raajimakers et al (2017) \\
\hline $\begin{array}{l}\text { Carballo-Magdaleno et }\left.a\right|^{29} \\
\text { (2011) }\end{array}$ & Kandasamy et al ${ }^{41}$ (2020) \\
\hline Rodriguz-Soriano et al ${ }^{19}$ (2005) & Bruel et $a /^{31}$ (2016) \\
\hline Keijer Veen et al ${ }^{22}$ (2007) & Chan et $a l^{27}(2020)$ \\
\hline Kist-Van Holthe et $a^{21}$ (2007) & Zaffanello et $a l^{26}$ (2010) \\
\hline Rakow et a/ ${ }^{38}$ (2019) & Ojala et al ${ }^{17}(2001)$ \\
\hline Bacchetta et $a^{25}$ (2009) & Porter et al ${ }^{20}$ (2006) \\
\hline \multicolumn{2}{|l|}{ Harer et $a l^{33}(2017)$} \\
\hline \multicolumn{2}{|l|}{ Jones et $a l^{16}(1997)$} \\
\hline Abitbol et al ${ }^{18}$ (2003) & \\
\hline
\end{tabular}

GFR, glomerular filtration rate.

186 615, they concluded that premature birth conferred a twofold increased risk of CKD and extremely premature birth conferred a threefold increased risk of CKD. ${ }^{37}$ This risk was found to be highest between ages 0-9 years and slightly weakened but still increased from ages 10-19 years. $^{37}$

\section{Blood pressure}

Twenty-three out of the thirty-one studies investigated BP as one of their outcome measures. ${ }^{17-1921-272931-3335363840-45}$ Fifteen found no significant difference in BP between study and control groups. ${ }^{17-19} 21$ 23-27 31-33 3538 41 Seven of these studies found no significant difference in BP between term babies and premature babies at differing ages, ranging from 1.5 to 27.6 years. ${ }^{19} 242527353841$ Six studies compared premature babies with and without different variables including exposure to betamethasone, exposure to indomethacin, presence or absence of nephrocalcinosis, having neonatal acute kidney injury, and having extrauterine growth restriction, intrauterine growth restriction or being appropriate for gestational age. ${ }^{172123253133}$ All six concluded no significant difference in BP between these groups of premature babies at differing ages, ranging from 2 to 19 years. ${ }^{172123253133}$ Zaffanello et al found no significant difference in BP between very low birth weight and extremely low birth weight infants at 5-6 years of age. ${ }^{26}$ Masqood et al also compared groups of extremely low birth weight children with no or varying severities of neonatal acute kidney injury and found no significant difference in BP at approximately $6-8$ years. ${ }^{32}$ 
It should be noted that both Zaffanello and Maqsood did not compared these BPs with term infants. ${ }^{26} 32$

Carballo-Magdaleno et al, Keijzer-Veen et al, Yael et al, South et al, Staub et al and Crump et alfound increased BP in premature children compared with controls. ${ }^{22} 2936404344$ Carballo-Magdaleno et al found that 2-year-old infants born prematurely had significantly higher BPs than 2-year-old infants born at term. ${ }^{29}$ Keijzer-Veen et al found significantly increased systolic BP in premature children compared with term children when BP was assessed at 20 years. ${ }^{22}$ Yael et al reported a $15.8 \%$ prevalence rate of systolic hypertension in their study group of premature children with very low birth weight when assessed at 10-13 years. ${ }^{43}$ This is compared with the general US paediatric population, which has a $1.6 \%$ prevalence rate of systolic hypertension. ${ }^{43}$ South et al found significantly higher BP in premature children compared with term children at 14 years of age. ${ }^{36}$ Staub et al found that systolic BP was significantly higher in premature boys compared with term boys; however, they did not find a significant difference in premature and term girls. ${ }^{44}$ They also noted that low birth weight was associated with higher BP in boys. ${ }^{44}$ Crump et al found that prematurity was associated with an increased risk of hypertension in early adulthood. ${ }^{40}$ They found that at 18-29 years of age, adjusted hazards ratios were 1.28 and 2.45 , respectively, for premature and extremely premature birth compared with term birth. ${ }^{40}$ Furthermore, at 30-43 years of age hazards ratios were calculated as 1.25 and 1.68 for premature and extremely

\begin{tabular}{|c|c|}
\hline $\begin{array}{l}\text { Studies that found a } \\
\text { significant difference in } \\
\text { BP between groups }\end{array}$ & $\begin{array}{l}\text { Studies that did not find a } \\
\text { significant difference in BP } \\
\text { between groups }\end{array}$ \\
\hline Crump et al ${ }^{37}$ (2019) & Finken et $\mathrm{al}^{23}$ (2008) \\
\hline Askenazi et a/45 (2021) & Masqood et al (2017) \\
\hline South et al ${ }^{36}(2019)$ & Vollsaeter et al ${ }^{35}(2018)$ \\
\hline Staub et $a l^{44}(2020)$ & Rakow et al ${ }^{24}(2008)$ \\
\hline Yael et al ${ }^{43}(2020)$ & Kandasamy et al ${ }^{41}$ (2020) \\
\hline $\begin{array}{l}\text { Carballo-Magdaleno et a }\left.\right|^{29} \\
\text { (2011) }\end{array}$ & Rodriguz-Soriano et al (2005) \\
\hline Keijer Veen et al (2007) & Kist-Van Holthe et $a l^{21}$ (2007) \\
\hline \multirow[t]{8}{*}{ Sanderson et al/2 (2020) } & Bruel et a/ ${ }^{31}(2016)$ \\
\hline & Chan et $\left.a\right|^{27}(2020)$ \\
\hline & Zaffanello et $a^{26}$ (2010) \\
\hline & Ojala et $a l^{17}(2001)$ \\
\hline & Rakow et al ${ }^{38}$ (2019) \\
\hline & Bacchetta et $a l^{25}$ (2009) \\
\hline & Harer et $\left.a\right|^{33}(2017)$ \\
\hline & Abitbol et al ${ }^{18}(2003)$ \\
\hline
\end{tabular}

BP, blood pressure. premature birth, respectively, when compared with fullterm birth. ${ }^{40}$ Table 3 shows all the studies that investigated $\mathrm{BP}$ and whether or not they found a significant difference between groups.

Sanderson et al found that of their 42 premature participants, approximately $14(33.3 \%)$ had elevated BPs at 15 years of age. ${ }^{42}$ Askenazi et al found that of their 923 extremely low gestational age participants at 22-26 months of age, approximately 212 (23\%) have a systolic BP $>95$ th percentile for their age and approximately 369 $(40 \%)$ had a diastolic BP $>95$ th percentile. ${ }^{45}$

\section{Proteinuria/albuminuria}

Nineteen studies commented on proteinuria or albuminuria. $^{15-22 ~ 24-263133363841-4345}$ Of these, 11 studies found no significant difference between study and control groups. 1720212426293133363841 Six out of these eleven studies compared term and premature infants at ages, ranging from approximately 0.5 to 14 years. ${ }^{19} 2433363841$ The other five studies compared groups of premature children with varying characteristics including neonatal AKI, low or extremely low birth weight, the presence of nephrocalcinosis and indomethacin exposure. For these studies outcomes were measured at 2-7.5 years. ${ }^{1720} 212631$

Seven studies commented on prevalence of proteinuria or albuminuria. ${ }^{15162225424345}$ Askenazi et al found that at 22-26 months, approximately $330(35.8 \%)$ of their 923 participants had a urine albumin/creatinine ratio greater than $30 \mathrm{mg} / \mathrm{g} .{ }^{45}$ Bacchetta et al found that 2 out of their 50 participants had moderate microalbuminuria at approximately 7 years of age. ${ }^{25}$ Jones et al found that 2 out of their cohort of 28 premature had microalbuminuria at $4-5$ years of age. ${ }^{16}$ Sanderson et al found approximately $5(11.9 \%)$ of their 42 premature children had microalbuminuria at 15 years of age. ${ }^{42}$ Keijer Veen et al reported microalbuminuria in two patients of their premature small for gestational age group. ${ }^{22}$ However, none of their participants in the premature appropriate for gestational age group or term group was found to have microalbuminuria. ${ }^{22}$ Yael et al found that the prevalence of microalbuminuria was $14.3 \%$, while the prevalence of proteinuria was $7.9 \%$ in their low birth weight premature cohort of 103 at 11.6 years. ${ }^{43}$ Finally, Downing et al found that 4 out of the 10 participants in their premature cohort with renal calcifications who received frusemide therapy, had trace proteinuria. ${ }^{15}$ The other 17 participants from their other 2 study groups did not have any proteinuria. ${ }^{15}$

Abitbol et al only had data for urine protein/creatinine ratios available for 10 out of 20 of their premature extremely low birth weight participants. ${ }^{18}$ Out of these 10 , those with low GFR ( $n=3)$ had significantly higher urine protein/creatinine ratios compared with the participants with normal GFR $(n=7)$ at follow-up. ${ }^{18}$ Follow-up ranged from 3.1 to 18.3 years. ${ }^{18}$

\section{Bias}

In all studies included in this review, bias was minimal. Some bias may be present in single-centre studies as these 
may only provide results from a particular population demographic. ${ }^{15-19} 22$ 24-28 30-343638 39414344 However, as this review correlates the results of numerous single-centre studies, this bias is minimised. Randomisation of study subjects was only done in 1 of the 31 included studies which was a randomised control trial where all study participants were premature. ${ }^{45}$ All other studies were observational, and randomisation was not possible as birth weight and gestational age are not variables that can be ethically influenced. ${ }^{15-44}$ Furthermore, 17 studies did not have term born controls. ${ }^{15-18} 20212325262831323439424345$ Abitbol et al did, however, match their study participants to age-matched, gender-matched and height-matched population norms when reviewing outcomes. ${ }^{18}$ Yael et al also did not have a term control group; however, they did compare their results to known population prevalence's. ${ }^{43}$

\section{DISCUSSION}

Thirty-one studies that assessed long-term kidney outcomes of premature infants were identified in this review. ${ }^{15-45}$ There was a relatively even split between the studies that investigated GFR as to whether there was or was not a significant difference between study and control groups. ${ }^{16-36} 38394143-45$ It should be noted that the studies which favoured no significant difference between premature and term participants investigated GFR in children from 0.5 to 13.5 years, while the studies that favoured a significant difference between the two populations measured outcomes at 7.5-20 years. ${ }^{19} 212224273536384144$ Thus, it is possible that in the short term, GFR is not significantly affected by prematurity. However, as the ex-premature population ages, their kidney function may become considerably diminished compared with the term population. This could possibly be due to the fact that premature infants start out with reduced nephron numbers.

From the 23 studies that investigated BP, 12 compared term and premature children. ${ }^{18} 1922242729353638404144$ Seven found no significant difference between premature children and term children, while five did find a significant difference. ${ }^{1819} 22242729353638404144$ The studies which found no significant difference measured outcomes from approximately 0.5 to 27.6 years of age while those that did find a significant difference, measured outcomes at 2-43 years of age. ${ }^{18} 1922242729353638404144$ Crump et al was the largest included study and also had one of the highest ratings on the quality assessment. ${ }^{40}$ It demonstrates that from 30 to 43 years of age, premature and extremely premature children are at a $25 \%$ and $68 \%$ greater risk of developing hypertension compared with controls. ${ }^{40}$ As with GFR, this may be because in early childhood the effects of prematurity on $\mathrm{BP}$ are not as obvious as the kidneys are able to compensate, or the reduced nephron number may not yet be significant. However, it is possible that as the ex-premature population ages, their initially reduced nephron number may no longer be able to compensate for BP.
From the 19 studies that investigated for microalbuminuria or proteinuria, most commented on prevalence as opposed to comparing groups. ${ }^{15-22} 24-263133363841-4345$ Only six studies, that commented on proteinuria or albuminuria, compared term children and premature children but all six of these studies found no significant difference between groups when assessed at 0.5-14 years of age. ${ }^{1923363841}$ Albuminuria or proteinuria are signs of kidney damage and progression of kidney disease. As with GFR and BP, it is possible that in childhood the kidneys are able to compensate for the shortened nephrogenesis. However, in the ageing population, ex-premature adults may be more likely to demonstrate markers of kidney disease or poor kidney function such as microalbuminuria or proteinuria sooner than their ex-term counterparts due to further reduction in an already deplete nephron reserve. Further, larger studies with longer follow-up periods are required to assess for microalbuminuria and proteinuria.

The risk of CKD is twofold and threefold greater in premature and extremely premature children, respectively, compared with those born at term as per Crump et $a l .{ }^{37}$ The risk of CKD over the age of 43 years cannot be commented on as it was not investigated in any of the included articles. The conclusion drawn by Crump et al is reliable, given their methodology and massive cohort size, despite other included articles not specifically commenting on CKD but GFR instead. The conclusion could be explained due to the decreased nephron endowment associated with prematurity. It should be noted that kidney function must be significantly impaired $($ GFR $<15)$ before evidence of kidney failure will be present clinically.

There are some limitations to our systematic review. The majority of the included studies were conducted in Caucasian predominant countries. Therefore, they do not reflect the true impact of prematurity of long-term kidney dysfunction as they do not encompass population rich countries including India, China and Nigeria where the highest number of premature births occur each year. This means the conclusions from this review do not apply to all ethnicities and cannot be generalised for non-Caucasian ethnic groups. Additionally, all the studies included in this review analysed kidney function through quantifiable measures such as blood tests. Clinically significant kidney outcomes, symptomatology, quality of life and kidney dysfunction associated mortality were not commented on or investigated in these studies. Finally, the majority of studies did not investigate outcomes over the age of 20 years. Two studies had participants up to the age of 43; however, the proportion of their study cohort over the age of 20 was minimal. Thus, this systematic review could only investigate long-term kidney outcomes of prematurity up until adolescence and early adulthood. Finally, only studies conducted after 1990 and written in English were considered for inclusion.

\section{CONCLUSION}

Prematurity is likely linked to an increased risk of kidney dysfunction and high BP in childhood and into early 
adulthood. The risk of CKD is twofold and threefold higher in premature and extremely premature children compared with those born at term. Further studies need to be conducted to investigate the effects of prematurity on long-term kidney health in the ageing population; reliable information at this time is only available up until the age of 43 years. Thus, kidney outcomes in the ex-premature population over the age of 43 years cannot be concluded from the current research. However, enough evidence is present to warrant ongoing monitoring of kidney function and BP in premature infants as they age in order to optimise and prevent earlier morbidity and mortality.

Contributors YK conceived the idea. AS performed the literature search. AS and YK evaluated the search results and AS extracted the data. AS and YK wrote the manuscript and edited subsequent and final drafts.

Funding The authors have not declared a specific grant for this research from any funding agency in the public, commercial or not-for-profit sectors.

Competing interests None declared.

Patient consent for publication Not required.

Provenance and peer review Not commissioned; externally peer reviewed.

Data availability statement Data sharing not applicable as no datasets generated and/or analysed for this study. No original data were generated for this study.

Supplemental material This content has been supplied by the author(s). It has not been vetted by BMJ Publishing Group Limited (BMJ) and may not have been peer-reviewed. Any opinions or recommendations discussed are solely those of the author(s) and are not endorsed by BMJ. BMJ disclaims all liability and responsibility arising from any reliance placed on the content. Where the content includes any translated material, BMJ does not warrant the accuracy and reliability of the translations (including but not limited to local regulations, clinical guidelines, terminology, drug names and drug dosages), and is not responsible for any error and/or omissions arising from translation and adaptation or otherwise.

Open access This is an open access article distributed in accordance with the Creative Commons Attribution Non Commercial (CC BY-NC 4.0) license, which permits others to distribute, remix, adapt, build upon this work non-commercially, and license their derivative works on different terms, provided the original work is properly cited, appropriate credit is given, any changes made indicated, and the use is non-commercial. See: http://creativecommons.org/licenses/by-nc/4.0/.

\section{ORCID iDs}

Ananya Sangla http://orcid.org/0000-0003-3524-9079

Yogavijayan Kandasamy http://orcid.org/0000-0002-7645-8398

\section{REFERENCES}

1 World Health Organization. March of dimes; the partnership for maternal, newborn \& child health; save the children. In: Born to son: the global action report on preterm birth, 2012.

2 Blencowe H, Cousens S, Oestergaard MZ, et al. National, regional, and worldwide estimates of preterm birth rates in the year 2010 with time trends since 1990 for selected countries: a systematic analysis and implications. Lancet 2012;379:2162-72.

3 Liu L, Oza S, Hogan D, et al. Global, regional, and national causes of under-5 mortality in 2000-15: an updated systematic analysis with implications for the sustainable development goals. The Lancet 2016;388:3027-35.

4 Barker DJ, Osmond C, Golding J, et al. Growth in utero, blood pressure in childhood and adult life, and mortality from cardiovascular disease. BMJ 1989;298:564-7.

5 Starr MC, Hingorani SR. Prematurity and future kidney health: the growing risk of chronic kidney disease. Curr Opin Pediatr 2018;30:228

6 Dover GJ. The Barker hypothesis: how pediatricans will diagnose and prevent common adult-onset diseases. Trans Am Clin Climatol Assoc 2009;120:199.
7 Barker DJP, Osmond C, Winter PD, et al. Weight in infancy and death from ischaemic heart disease. The Lancet 1989;334:577-80.

8 Heindel JJ, Vandenberg LN. Developmental origins of health and disease: a paradigm for understanding disease cause and prevention. Curr Opin Pediatr 2015;27:248.

9 Luyckx VA, Brenner BM. Low birth weight, nephron number, and kidney disease. Kidney Int Supp/ 2005;68:S68-77.

10 Brenner BM, Garcia DL, Anderson S. Glomeruli and blood pressure. less of one, more the other? Am J Hypertens 1988;1:335-47.

11 Ryan D, Sutherland MR, Flores TJ, et al. Development of the human fetal kidney from mid to late gestation in male and female infants. EBioMedicine 2018;27:275-83.

12 Luyckx VA, Bertram JF, Brenner BM, et al. Effect of fetal and child health on kidney development and long-term risk of hypertension and kidney disease. Lancet 2013;382:273-83.

13 Brenner BM, Chertow GM. Congenital oligonephropathy and the etiology of adult hypertension and progressive renal injury. Am J Kidney Dis 1994;23:171-5.

14 Moher D, Liberati A, Tetzlaff J. RESEARCH METHODS \& REPORTING-Preferred reporting items for systematic reviews and meta-analyses: the PRISMA statement-David Moher and colleagues introduce PRISMA, an update of the QUOROM guidelines for reporting systematic reviews and meta-analyses. $B M J$ 2009;339:332.

15 Downing GJ, Egelhoff JC, Daily DK, et al. Kidney function in very low birth weight infants with furosemide-related renal calcifications at ages 1 to 2 years. J Pediatr 1992;120:599-604.

16 Jones CA, King S, Shaw NJ, et al. Renal calcification in preterm infants: follow up at $4-5$ years. Arch Dis Child Fetal Neonatal Ed 1997;76:F185-9.

17 Ojala R, Ala-Houhala M, Ahonen S, et al. Renal follow up of premature infants with and without perinatal indomethacin exposure. Arch Dis Child Fetal Neonatal Ed 2001;84:28F-33.

18 Abitbol CL, Bauer CR, Montané B, et al. Long-Term follow-up of extremely low birth weight infants with neonatal renal failure. Pediatr Nephrol 2003;18:887-93.

19 Rodríguez-Soriano J, Aguirre M, Oliveros R, et al. Long-Term renal follow-up of extremely low birth weight infants. Pediatr Nephrol 2005;20:579-84.

20 Porter E, McKie A, Beattie TJ, et al. Neonatal nephrocalcinosis: long term follow up. Arch Dis Child Fetal Neonatal Ed 2006;91:F333-6.

21 Kist-van Holthe JE, van Zwieten PHT, Schell-Feith EA, et al. Is nephrocalcinosis in preterm neonates harmful for long-term blood pressure and renal function? Pediatrics 2007;119:468-75.

22 Keijzer-Veen MG, Kleinveld HA, Lequin MH, et al. Renal function and size at young adult age after intrauterine growth restriction and very premature birth. Am J Kidney Dis 2007;50:542-51.

23 Finken MJJ, Keijzer-Veen MG, Dekker FW, et al. Antenatal glucocorticoid treatment is not associated with long-term metabolic risks in individuals born before 32 weeks of gestation. Arch Dis Child Fetal Neonatal Ed 2008;93:F442-7.

24 Rakow A, Johansson S, Legnevall L, et al. Renal volume and function in school-age children born preterm or small for gestational age. Pediatr Nephrol 2008;23:1309-15.

25 Bacchetta J, Harambat J, Dubourg L, et al. Both extrauterine and intrauterine growth restriction impair renal function in children born very preterm. Kidney Int 2009;76:445-52.

26 Zaffanello M, Brugnara M, Bruno C, et al. Renal function and volume of infants born with a very low birth-weight: a preliminary crosssectional study. Acta Paediatr 2010;99:1192-8.

27 Chan PYL, Morris JM, Leslie Gl, et al. The long-term effects of prematurity and intrauterine growth restriction on cardiovascular, renal, and metabolic function. Int J Pediatr 2010;2010:1-10.

28 Giapros V, Tsoni C, Challa A, et al. Renal function and kidney length in preterm infants with nephrocalcinosis: a longitudinal study. Pediatr Nephrol 2011;26:1873-80.

29 Carballo-Magdaleno D, Guízar-Mendoza JM, Amador-Licona N, et al. Renal function, renal volume, and blood pressure in infants with antecedent of antenatal steroids. Pediatr Nephrol 2011;26:1851-6.

30 Starzec K, Klimek M, Grudzień A, et al. Longitudinal assessment of renal size and function in extremely low birth weight children at 7 and 11 years of age. Pediatr Nephrol 2016;31:2119-26.

31 Bruel A, Rozé J-C, Quere M-P, et al. Renal outcome in children born preterm with neonatal acute renal failure: IRENEO-a prospective controlled study. Pediatr Nephrol 2016;31:2365-73.

32 Maqsood S, Fung N, Chowdhary V, et al. Outcome of extremely low birth weight infants with a history of neonatal acute kidney injury. Pediatr Nephrol 2017;32:1035-43.

33 Harer MW, Pope CF, Conaway MR, et al. Follow-up of acute kidney injury in neonates during childhood years (fancy): a prospective cohort study. Pediatr Nephrol 2017;32:1067-76. 
34 Raaijmakers A, Zhang Z-Y, Levtchenko E, et al. Ibuprofen exposure in early neonatal life does not affect renal function in young adolescence. Arch Dis Child Fetal Neonatal Ed 2018;103:F107-11.

35 Vollsæter M, Halvorsen T, Markestad T, et al. Renal function and blood pressure in 11 year old children born extremely preterm or small for gestational age. PLoS One 2018;13:e0205558.

36 South AM, Nixon PA, Chappell MC, et al. Renal function and blood pressure are altered in adolescents born preterm. Pediatr Nephrol 2019;34:137-44.

37 Crump C, Sundquist J, Winkleby MA, et al. Preterm birth and risk of chronic kidney disease from childhood into mid-adulthood: national cohort study. BMJ 2019;365:11346.

38 Rakow A, Laestadius Åsa, Liliemark U, et al. Kidney volume, kidney function, and ambulatory blood pressure in children born extremely preterm with and without nephrocalcinosis. Pediatr Nephrol 2019;34:1765-76.

39 Horie A, Abe Y, Koike D, et al. Long-term renal follow up of preterm neonates born before 35 weeks of gestation. Pediatr Int 2019;61:1244-9.

40 Crump C, Sundquist J, Sundquist K. Risk of hypertension into adulthood in persons born prematurely: a national cohort study. Eur Heart J 2020;41:1542-50.
41 Kandasamy Y, Rudd D, Lumbers ER, et al. An evaluation of preterm kidney size and function over the first two years of life. Pediatr Nephrol 2020;35:1477-82

42 Sanderson KR, Chang E, Bjornstad E, et al. Albuminuria, hypertension, and reduced kidney volumes in adolescents born extremely premature. Front Pediatr 2020;8:230.

43 Yael B, Roi T, Nir S, et al. Early detection of renal dysfunction in adolescents aged 10-13 years born with very low birth weight. Arch Clin Biomed Res 2020;04:184-94.

44 Staub E, Urfer-Maurer N, Lemola S, et al. Comparison of blood pressure and kidney markers between adolescent former preterm infants and term controls. Children 2020;7:141

45 Askenazi DJ, Heagerty PJ, Schmicker RH. The impact of erythropoietin on short- and long-term kidney-related outcomes in neonates of extremely low gestational age. Results of a multicenter, double-blind, placebo-controlled randomized clinical trial. J Pediatr 2021;232:65-72.

46 Wells G, Shea B, O'Connell D. The newcastle-ottawa scale (NOS) for assessing the quality of nonrandomised studies in meta-analyses, 2013. Available: http://www.ohri.ca/programs/clinical_epidemiology/ oxford.asp 